\title{
Training in emerging advances in chronic hepatitis C infection in Pakistan: the Teach - Pak project
}

This article was published in the following Dove Press journal: Advances in Medical Education and Practice

\section{Faisal W Ismail \\ Shahab Abid \\ Minaz Mawani \\ Wasim Jafri \\ Saeed S Hamid}

Department of Medicine, Section of Gastroenterology, The Aga Khan University, Karachi, Pakistan
Correspondence: Faisal Ismail Department of Medicine, Section of Gastroenterology, Aga Khan University Hospital, Stadium Road, Karachi 74800, Pakistan

Tel +92213493005 I

Fax +92 2134934294

Email faisal.ismail@aku.edu
Purpose: Viral hepatitis B and C represent the primary health challenge confronting Asia and Pakistan. With direct-acting antiviral therapy for hepatitis $\mathrm{C}$, patients will be treated by general physicians (GPs) and will need training through continuing medical education (CME). Blended learning is a combination of didactic teaching with online, self-paced learning, and it has not been evaluated as a CME tool for general physicians. We aimed to compare the change in physician's knowledge about chronic viral hepatitis following a blended learning educational program.

Methods: Participants enrolled in a 6 week blended learning program comprising three modules, each of 2 weeks duration. These were: 1) epidemiology and prevention of viral hepatitis; 2) diagnosis and assessment of hepatitis; and 3) treatment of hepatitis. Activities were primarily web based with some face-to-face interactive sessions. All study material was available on the Teach - Pak website. Discussions, questions, and comments were encouraged. An overall preand postintervention knowledge assessment was performed, in addition to individual module assessments.

Results: A total of 48 participants completed the program; 39 passed ( $81.25 \%)$. The participants were from diverse backgrounds with variable previous training. The pass rate rose from $16.1 \%$ at the start of the program to $81.2 \%$ at the conclusion. The mean pretest score was 26.0 (standard deviation $=4.36$ ), while the mean posttest score was 34.6 (standard deviation $=5.15$ ), showing an increase in the mean score of 8.56 points. Eighty four percent had completed at least one credit hour for CME as compared to those who did not pass the posttest $(44.4 \% p$-value $=0.02)$. No significant differences in results of posttest were observed in the categories of participant's age, years since graduation, or years of experience. The participants were satisfied with the blended learning mode of teaching.

Conclusion: Blended learning is an efficient way to impart hepatitis CME to a diverse group of postgraduate physicians.

Keywords: blended learning, CME, hepatitis, postgraduate physicians, teaching

\section{Introduction}

Hepatitis $\mathrm{B}(\mathrm{HBV})$ and $\mathrm{C}(\mathrm{HCV})$ virus infection represent the primary health challenge confronting the developing world today. With the major burden of disease in Asia, these viruses represent a major source of morbidity and mortality in the next few decades in this region. ${ }^{1}$

The prevalence of HBV and HCV in Pakistan is $2.5 \%$ and $4.8 \%$, respectively. ${ }^{2}$ With a population of 180 million, this translates to a health care burden of 12 million people suffering from these viruses. Poor screening methods, inadequate health care delivery, and lack of awareness has ensured that these viruses continue to propagate in the country unabated. ${ }^{2,3}$ 
Given the high prevalence of $\mathrm{HCV}$, urgent and sustained action is required on a number of fronts in order to halt the spread and eradicate HCV infection in Pakistan. One of the most important steps in this regard is to create awareness regarding the diagnosis, prevention, and treatment of $\mathrm{HCV}$ patients among health care professionals. With the advent of direct-acting antiviral therapy, it is anticipated that a large population of patients will be treated by general physicians (GPs). It is therefore imperative that they are properly trained, not only in the treatment, but in all aspects of HCV disease, to avoid mismanagement.

Continuing medical education (CME) consists of educational activities which serve to maintain, develop, or increase the knowledge, skills, and professional performance and relationships that a physician uses to provide services for patients, the public, or the profession. Content for these programs is developed, reviewed, and delivered by faculty members who are experts in their individual clinical areas. ${ }^{4}$

Blended learning is a relatively new concept in educational practice, with few references predating $2001 .^{5}$ It is used interchangeably with the term hybrid learning. It is the balanced utilization of computer-supported collaboration and communication tools, with self-paced learning tools/ materials (websites, online resources, etc), in conjunction with in-class teaching practices by higher education faculty.,

The basic idea behind blended learning is to design a course that integrates the best pedagogical aspects of both face-to-face learning and online learning. ${ }^{7}$ There are several noted limitations with pure online and distance learning, particularly for learners who are less independent and require consistent direction from an instructor. Consequently, the blended learning approach is intended to mitigate the challenges caused by completely eliminating in-person classroom contact, while still offering the opportunity for students, faculty, and administrators to reap the benefits of online learning. ${ }^{8}$

Traditional face-to-face training can be prohibitively expensive and places significant strain on human and financial resources. ${ }^{9}$ Blended approaches help to reduce the cost of training and education, while also providing face-to-face learning to appease the need for feedback and engagement. ${ }^{10}$

e-learning as a mode of medical education has been well described in literature. ${ }^{11}$ It has been used in nursing education, ${ }^{12}$ in the successful training of health professionals in Bangladesh, ${ }^{13}$ and as part of a gastroenterology training curriculum as well. ${ }^{14}$ Based on these encouraging data, we proposed an online, blended learning curriculum for health professionals in Pakistan for the treatment and management of hepatitis $\mathrm{C}$.

\section{Aim}

To compare the change in health care professional's knowledge about epidemiology, prevention, diagnosis, and management of chronic hepatitis $\mathrm{C}$ following a blended learning educational program - the Training in Emerging Advances in the Management of Chronic Hepatitis $\mathrm{C}$ infection for Healthcare professionals in Pakistan, The Teach - Pak project.

\section{Methods}

\section{Study design}

A before-and-after study design was used. Participant's increase in knowledge was assessed by difference in test scores pre- and postintervention regarding chronic $\mathrm{HCV}$.

\section{Funding}

This project was enabled by a grant from the International Coalition of Hepatology educational providers to the Pakistan Society for the Study of Liver Diseases to conduct an educational activity on various aspects of hepatitis $\mathrm{C}$. The grant was received after a competitive process of application.

\section{Course participants}

Participants were residents-in-training and GPs, both from government and private hospitals, who were active in the management and treatment of hepatitis $\mathrm{C}$ from the province of Sind in Pakistan. Our hospital maintained a list of GPs in the area, and these were the ones we initially invited to participate.

We also recruited 12 doctors from the "Chief Ministers Program for hepatitis C free Sind." This program is responsible for free provision of vaccines and treatment of hepatitis and is the largest program in the province catering to hepatitis management. It is, therefore, extremely important that the doctors in this program are adequately trained for this responsibility. We felt that targeting this community of health care provider (HCP) would have most impact.

\section{Course faculty}

Faculty were consultant gastroenterologists. Three faculty members were professors, and one was an assistant professor. All faculties worked at a university teaching hospital and were extensively experienced in under and postgraduate teaching.

\section{Curriculum development process}

The curriculum was developed using educational material that was available for use through the resources of the American Association for the Study of Liver Diseases, The European Association for the Study of the Liver, the 
Asia-Pacific Association for the Study of the Liver, and the Centre for Disease Control and Prevention. All material was reviewed by all faculties for accuracy and suitability. No industry funding was accepted or branded, and none of the faculty had relevant disclosures with regard to the curriculum development. All study material was updated and properly referenced at the time of instruction delivery.

\section{Components of curriculum}

The study material was in the form of presentations, review articles, and videos.

\section{Delivery of course curriculum}

Educational training focused on three areas in the form of modules. These three modules were

1. Epidemiology and prevention of $\mathrm{HCV}$

2. Diagnosis and assessment of severity of $\mathrm{HCV}$

3. Treatment of HCV.

A preliminary meeting was held at the start of the course, where the modules were defined and a preintervention knowledge assessment was done, through a 50 single-besttype multiple choice question (MCQ) paper. This was the baseline participant knowledge comprising content from all three modules.

The duration of each module was 2 weeks. Modules were primarily web based with a face-to-face interactive session at the end of each session, where the module was discussed and any unmet educational needs identified and solved. This session was held in the university campus, and required the physical presence of the participants every 2 weeks for a 2 hour session. There were a total of four faceto-face meetings - an introductory meeting at the start of the course, followed one each at the end of every module. After ensuring that the content had been delivered successfully, the participants proceeded to the next module.

\section{Website development and its features}

The URL of the website was pssld-trainings.com. ${ }^{15}$ On reaching the homepage, participants logged in with individual usernames and passwords to access the material on the website.

Each module had its own dropdown menu where all the material was posted. On clicking on the link, the article, video, or presentation would open in a different window. The presentation and articles were in pdf format, which could be viewed or saved by the participants.

Parallel to this, a discussion forum was linked, where participants were encouraged to post comments and articles and discuss relevant topics in the discussion threads for each individual module.

Each participant's frequency of log-in, posting of comment, and viewing of material was tracked. These were discussed during the review meetings every couple of weeks in an effort to keep the audience engaged and motivated.

\section{Method of evaluation Pretest evaluation}

A single-best-type MCQ paper comprising 50 questions.

\section{Period testing}

Each module had a postintervention assessment, which comprised 20 single-best-type MCQ questions that assessed only upon completion of the module.

\section{Continuous evaluation}

This was done through activity on the discussion thread, posting comments and articles, asking questions, and group interaction. Questions and case scenarios were posted here for the participants to comment on and generate discussion. Individual test scores were not posted to protect privacy.

\section{Final evaluation}

At the end of the last module, the participants sat the initial pretest paper again. This was done so that a pre- and postintervention difference in knowledge could be assessed. None of the participants were aware that they would be sitting for the same test again. Passing percentage in all evaluation tests was $60 \%$.

After successful completion of the course, participants were certified as hepatitis care providers by the International Coalition of Hepatology educational providers and Pakistan Society for the Study of Liver Diseases.

\section{Primary outcome measure}

Improvement in participant's knowledge as assessed by difference in test scores before and after taking the course was the primary outcome measure.

\section{Data analysis}

All analyses were conducted using the Statistical Package for Social Sciences (version 19; IBM Corporation, Armonk, NY, USA). Paired sample $t$-tests were used to test for statistical significance between scores of pre- and posttests. We examined characteristics between the groups of posttest results using a $\chi^{2}$ or a Fisher's exact test. Continuous variables were assessed using independent sample $t$-test. All $p$-values were two sided and considered as statistically significant if $<0.05$. 


\section{Results}

The course was offered twice in 6 months. Figure 1 describes the flow of the participants. A total of 73 people were contacted and $60(82.1 \%)$ agreed to participate in the course. A total of 48 participants completed the Teach - Pak training program. On average, participants had 7.81 years (standard deviation $[\mathrm{SD}]=7.19$ ) of clinical experience, ranging from 2 to 35 years. A higher proportion of participants were GPs (treating adults and children) (45.8\%), while 27.1\% were adult internists. Almost half (54.2\%) of the participants had attended 1-2 hours of CME on gastroenterology or hepatology during last 1 year. About $73 \%$ of the participants had attended a structured residency program. A higher proportion of participants were from private practice (54.2\%). Table 1 shows characteristics of the course participants.

The pass rate rose from $16.1 \%$ at the start of the program to $81.2 \%$ at the conclusion. Participant's knowledge was assessed by the difference in test scores pre- and postintervention. The mean pretest score was $26.0(\mathrm{SD}=4.36)$, while the mean posttest score was $34.6(\mathrm{SD}=5.15)$, showing an increase in the mean score of 8.56 points $(\mathrm{SD}=5.66)$. This increase was statistically significant $(95 \%$ confidence interval: 6.91-10.20) according to paired $t$-test comparison of pre- and posttest results. Figure 2 shows participant's results on pre- and posttests, while Figure 3 shows the distribution of marks of the participants in the pre- and posttest groups. Participants were required to score at least $60 \%$ to pass the test.

Table 2 shows characteristics of participants based on the results they obtained. Among the 39 participants who had passed the posttest, $73.7 \%$ had completed their residency, 16 (42.1\%) were working as GPs, $12(31.6 \%)$ were internists, and $10(26.3 \%)$ were trainees. A significantly higher number of participants who passed the test $(84.2 \%)$ had completed at least one credit hour for CME as compared to those who

Table I Characteristics of the course participants

\begin{tabular}{ll}
\hline Variables & $\mathbf{n}(\%)$ \\
\hline Age, years, mean (SD) & $33.8(7.57)$ \\
Gender & \\
Male & $28(58.3 \%)$ \\
Female & $20(41.7 \%)$ \\
Years since graduation, mean (SD) & $9.6(7.44)$ \\
Years of clinical experience, mean (SD) & $7.81(7.19)$ \\
Attended a structured residency program & \\
Yes & $35(72.9 \%)$ \\
No & $12(25 \%)$ \\
Type of practice & \\
Trainee & $12(25 \%)$ \\
General practitioner & $22(45.8 \%)$ \\
Internist & $13(27.1 \%)$ \\
Number of CME hours attended & \\
None & $11(22.9 \%)$ \\
I-2 hours & $26(54.2 \%)$ \\
More than 2 hours & $10(20.8 \%)$ \\
Number of logins, median (IQR), range: 0-I2I & $40(58.5)$ \\
Number of comments, median (IQR), range: 0-63 & $1.5(4.0)$ \\
Number of tasks viewed, median (IQR), range: $0-189$ & $43.0(61.7)$ \\
Attendance in sessions & \\
All 4 sessions & $29(60.4 \%)$ \\
3 sessions & $13(27.1 \%)$ \\
I or 2 sessions & $6(12.5 \%)$ \\
\hline Abevians: CME, con
\end{tabular}

Abbreviations: CME, continuing medical education; IQR, interquartile range; SD, standard deviation.

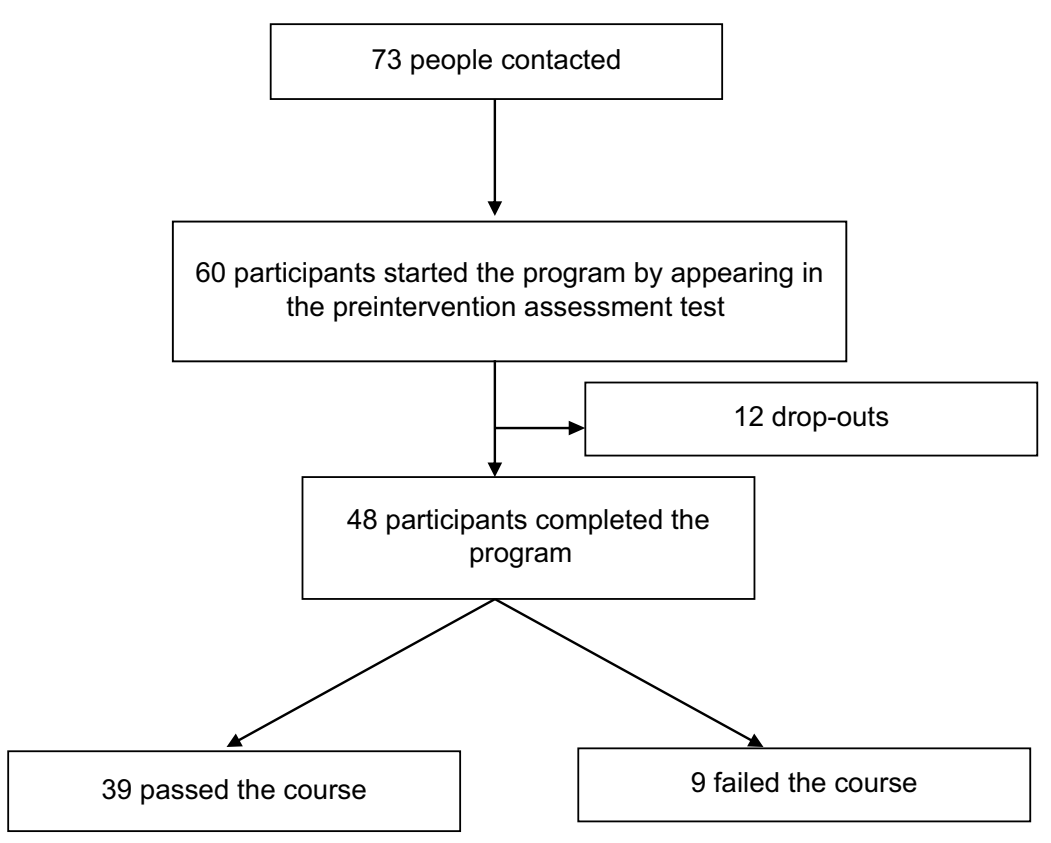

Figure I Flow of the program. 
did not pass the posttest $(44.4 \% p$-value $=0.02)$. No significant differences in results of posttest were observed in the categories of participant's age, years since graduation, and years of clinical experience. Surprisingly, the participants who failed the course on posttest had higher attendance in the face-to-face sessions, higher number of logins and tasks viewed on the website, and higher number of comments on the given tasks during the entire course as compared to those who passed the posttest. However, the difference was found to be statistically insignificant.

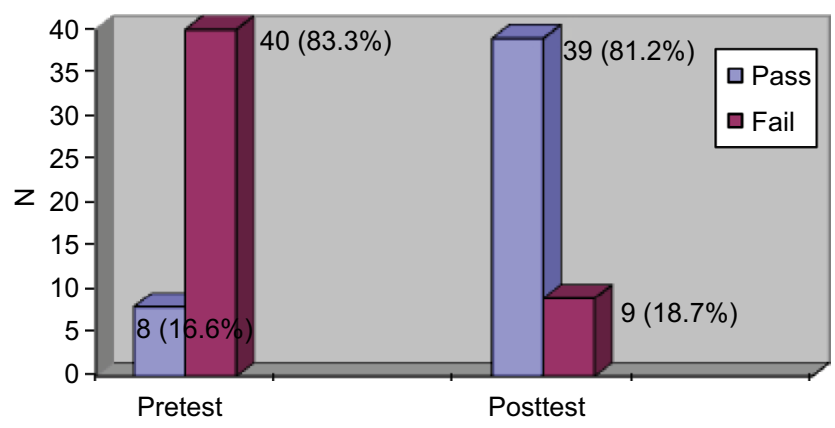

Figure 2 Results of 48 participants on pretests and posttests.
Table 3 shows the evaluation of the program by the participants. The majority of participants were satisfied with the course and thought that blended learning was a good method of teaching. A significant number felt that the traditional mode of class room didactic teaching would have been preferable. However, most of them would not only attend such a program again, but would also be liable to recommend it to a colleague.

\section{Discussion}

This was the first CME activity of its kind in Pakistan which adopted the blended learning method of curriculum delivery to a diverse group of physicians. In the past, blended learning has mainly been utilized in a class room setting for a particular course for a predominantly homogenous student group.

Our results showed that the intervention was successful in improving the overall knowledge about HCV management in the group. In addition, the program was well received by the participants, and there was good acceptance of this method of curriculum delivery, which allowed the participants to study at their own pace.

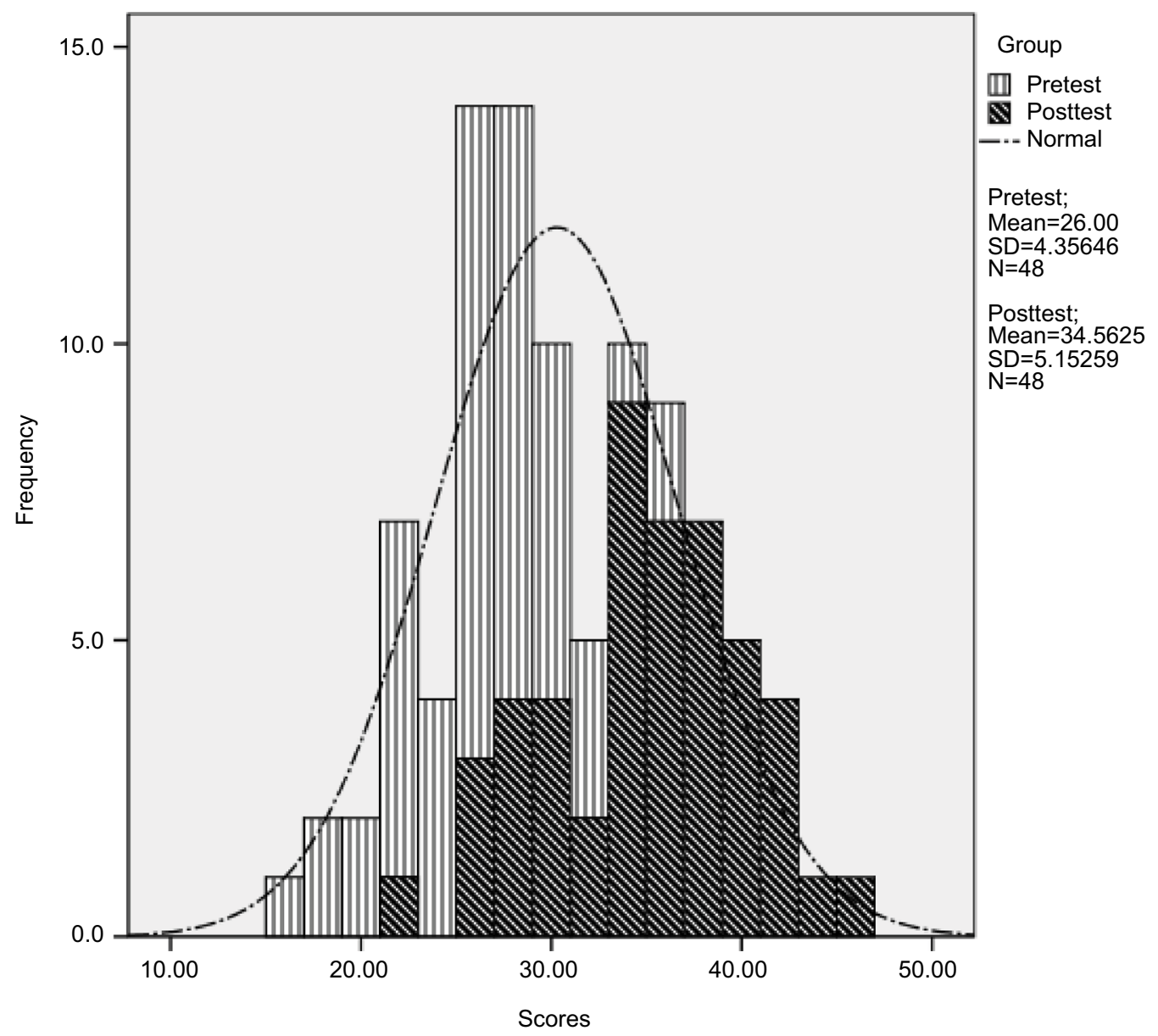

Figure 3 Distribution of participant's scores on pretests and posttests. 
Table 2 Characteristics of participants across the groups of posttest results

\begin{tabular}{|c|c|c|c|}
\hline Characteristics & Pass, $n=39$ & Fail, $n=9$ & p-value* \\
\hline Age, years, mean (SD) & $33.4 I(6.8)$ & $35.44(10.3)$ & 0.58 \\
\hline Gender & & & 0.27 \\
\hline Male & $21(53.8 \%)$ & 7 (77.8\%) & \\
\hline Female & $18(46.2 \%)$ & $2(22.2 \%)$ & \\
\hline Years since graduation, mean (SD) & $9.08(6.6)$ & $11.78(10.3)$ & 0.33 \\
\hline Years of clinical experience, mean (SD) & $7.21(6.1)$ & $10.33(10.7)$ & 0.24 \\
\hline Attended a structured residency program & & & 1.00 \\
\hline Yes & $28(73.7 \%)$ & 7 (77.8\%) & \\
\hline No & $10(26.3 \%)$ & $2(22.2 \%)$ & \\
\hline Type of practice & & & 0.35 \\
\hline Trainee & $10(26.3 \%)$ & $2(22.2 \%)$ & \\
\hline General & $16(42.1 \%)$ & $6(66.7 \%)$ & \\
\hline Internist & $12(31.6 \%)$ & I (II.I\%) & \\
\hline Number of CME hours attended & & & 0.02 \\
\hline None & $6(15.8 \%)$ & $5(55.6 \%)$ & \\
\hline At least one credit hour & $32(84.2 \%)$ & $4(44.4 \%)$ & \\
\hline Attendance & & & 0.36 \\
\hline Attended all 4 sessions & $22(56.4 \%)$ & 7 (77.8\%) & \\
\hline Attended 3 sessions & II (28.2\%) & $2(22.2 \%)$ & \\
\hline Less than 3 sessions & $6(15.4 \%)$ & $0(0.0 \%)$ & \\
\hline Number of logins, median (IQR) & $36(59)$ & $42(68)$ & 0.36 \\
\hline Number of comments, median (IQR) & I (4) & $3(7.5)$ & 0.36 \\
\hline Number of tasks viewed, median (IQR) & $41(49)$ & $56(62.5)$ & 0.09 \\
\hline Pretest grade & & & 0.62 \\
\hline Pass & 7 (I7.9\%) & I (II.I\%) & \\
\hline Fail & $32(82.1 \%)$ & $8(88.9 \%)$ & \\
\hline
\end{tabular}

Notes: *Paired $t$-test (means) or $\chi^{2}$ test (percentages). Note that for one participant, some of the data points were missing; therefore, variable categories do not add to $100 \%$. Abbreviations: CME, continuing medical education; IQR, interquartile range; SD, standard deviation.

Table 3 Evaluation of the participants regarding blended learning course $(n=48)$

\begin{tabular}{llll}
\hline S \# & Statement & Yes & No \\
\hline I & Were you largely satisfied with the quality of the course? & 48 & 0 \\
2 & Do you think blended learning is a good method of imparting CME? & 43 & 5 \\
3 & Would you have preferred a traditional class room method of delivery? & 29 & 19 \\
4 & Would you consider attending such a course again? & 43 & 5 \\
5 & Would you be likely to recommend this mode of teaching to your colleagues? & 48 & 0 \\
\hline
\end{tabular}

Abbreviation: CME, continuing medical education.

Our results show that years since graduation or clinical experience do not impact the performance in a blended learning program. However, specialists tended to perform better, as well as people who attended at least one CME a year. This may imply that this cohort is more likely to take to a blended learning program, as they are in the habit of focused reading and interested in upgrading their knowledge via CME.

Likewise, GPs may be more likely to do poorly, as they may not be able to commit to the time obligation a blended learning program demands, due to the burden of practice. Generally in Pakistan, GPs have very busy practices, as they cater to women, children, and adults, and practice late hours as well, in contrast to specialists who have a more constrained practice.
We used surrogate markers like attendance in the program, frequency of log-in, comments, and tasks viewed to judge participant involvement with the program. Interestingly, none of these were statistically significant between the participants who passed or failed. This may be due to the small numbers in each group, but also reflects that reading the text and participating in a few discussions may be sufficient for knowledge transfer.

Interestingly, while the majority of participants were satisfied with the course and thought that blended learning was a good method of teaching, a significant number felt that the traditional mode of class room didactic teaching would have been preferable. In our experience, these were participants who were older and/or did not have the computer skills that 
were required for the program. This is an important point to keep in mind when designing e-learning programs, as content delivery may not have the desired outcome if the cohort does not have similar skills.

The results from our study suggest that use of a blended learning program can successfully improve health care professional's knowledge. This inexpensive and practical intervention can be used to educate health care professionals about other common hepatic diseases such as HBV, nonalcoholic steatohepatitis, etc, which will enable them to provide better and updated health care to their patients. In addition, this program can also be implemented to a wider population.

Our study had the following limitations. Although study participants were from both private and public sector hospitals with variable training and experience, the fact that they were a small group of individuals from one region of the country makes the generalizability of this study limited to a wider population. Second, the implementation of this webbased program requires good internet connectivity, which may not be available in all areas of a low-income country such as Pakistan. Furthermore, the program requires the participants to have reasonable preexisting computer skills.

It would be important to study whether such programs translate into better patient care. This is a research question of a study presently underway in our institution. A more simplified version of this CME may also be considered, where the face-to-face sessions may be done online as well, and where the whole group need not assemble at one point but may contact the trainers by appointment as needed.

Pakistan has among the world's highest rates of mobile phone usage, and data charges for internet connectivity are competitive. We feel that the blended/online mode of CME delivery is a highly underutilized mode of study and has great potential to impart knowledge to remotely situated physicians who would otherwise have no access to traditional CMEs. This would be an efficient way of recruiting and maintaining the interest of physicians to keep them engaged with the CME process so that, ultimately, patient outcomes may improve.

\section{Conclusion}

The Teach - Pak project successfully imparted HCV CME to a diverse group of physicians through a blended learning curriculum. We hope to continue this project, improving it further and taking it nationwide.

\section{Disclosure}

The authors report no conflicts of interest in this work.

\section{References}

1. Mohd Hanafiah K, Groeger J, Flaxman AD, Wiersma ST. Global epidemiology of hepatitis $\mathrm{C}$ virus infection: new estimates of agespecific antibody to HCV seroprevalence. Hepatology. 2013;57(4): 1333-1342.

2. Qureshi H, Bile KM, Jooma R, Alam SE, Afridi HU. Prevalence of hepatitis B and C viral infections in Pakistan: findings of a national survey appealing for effective prevention and control measures. East Mediterr Health J. 2010;16 Suppl:S15-S23.

3. Jamil MS, Ali H, Shaheen R, Basit A. Prevalence, knowledge and awareness of hepatitis $\mathrm{C}$ among residents of three Union Councils in Mansehra. J Ayub Med Coll Abbottabad. 2010;22(3):192-196.

4. Accreditation Council for Continuing Medical Education. CME Content: Definition and Examples. Chicago, IL: Accreditation Council for Continuing Medical Education. Available from: http://www.accme.org/ requirements/accreditation-requirements-cme-providers/policies-anddefinitions/cme-content-definition-and-examples. Accessed February 14, 2012.

5. Bliuc AM, Goodyear P, Ellis RA. Research focus and methodological choices in studies into students' experiences of blended learning in higher education. Internet High Educ. 2007;10(4): 231-244.

6. Ocak MA. Blend or no to blend: a study examining faculty members perceptions of blended learning. World JEduc Tech. 2010;2(3):196-210.

7. Dorrian J, Wache D. Introduction of an online approach to flexible learning for on-campus and distance education students: lessons learned and ways forward. Nurse Educ Today. 2009;29(2):157-167.

8. US Department of Education. Evaluation of Evidence-Based Practices in Online Learning. Washington, DC: US Department of Education; 2010. Available from: https://www2.ed.gov/rschstat/eval/tech/evidencebased-practices/finalreport.pdf. Accessed June 22, 2015.

9. Marrinan H, Firth S, Hipgrave D, Jimenez-Soto E. Let's take it to the clouds: the potential of educational innovations, including blended learning, for capacity building in developing countries. Int $J$ Health Policy Manag. 2015;4(9):571-573.

10. Maloney S, Haas R, Keating JL, et al. Breakeven, cost benefit, cost effectiveness, and willingness to pay for web-based versus face-to-face education delivery for health professionals. J Med Internet Res. 2012;14(2):e47.

11. Masic I. E-learning as new method of medical education. Acta Inform Med. 2008;16(2):102-117.

12. Hsu LL, Hsieh SI. Factors associated with learning outcome of BSN in a blended learning environment. Contemp Nurse. 2011;38(1-2):24-34.

13. O'Brien L, Broom L, Ullah MM. Outcomes and participant experience of an online train-the-trainer program for Bangladeshi health professionals: a case study evaluation. J Contin Educ Health Prof. 2015;35(1):46-56.

14. Feist M, Ciccarelli M, McFerron BA, Molleston JP. Methods and effects of a case-based pediatric gastroenterology online curriculum. J Pediatr Gastroenterol Nutr. 2013;56(2):161-165.

15. Teach-Pak - A Project of PSSLD. Available from: Pssld-training.com. N.p., 2016. Accessed April 3, 2016. 
Advances in Medical Education and Practice

Dovepress

\section{Publish your work in this journal}

Advances in Medical Education and Practice is an international, peerreviewed, open access journal that aims to present and publish research on Medical Education covering medical, dental, nursing and allied health care professional education. The journal covers undergraduate education, postgraduate training and continuing medical education

including emerging trends and innovative models linking education, research, and health care services. The manuscript management system is completely online and includes a very quick and fair peer-review system. Visit http://www.dovepress.com/testimonials.php to read real quotes from published authors.

Submit your manuscript here: http://www.dovepress.com/advances-in-medical-education-and-practice-journal 